\title{
A NOTE ON THE MAXIMAL NUMERICAL RANGE
}

\author{
ILYA M. SPITKOVSKY
}

Abstract. We show that the maximal numerical range of an operator has a non-empty intersection with the boundary of its numerical range if and only if the operator is normaloid. A description of this intersection is also given.

Mathematics subject classification (2010): 47A12, 47B15.

Keywords and phrases: Numerical range, maximal numerical range, normaloid operator.

\section{REFERENCES}

[1] Jor-Ting Chan And Kong Chan, An observation about normaloid operators, Operators and Matrices 11 (2017), 885-890.

[2] J. B. Conway, The theory of subnormal operators, Mathematical Surveys and Monographs, vol. 36, American Mathematical Society, Providence, RI, 1991.

[3] Hwa-Long Gau And PeI YuAn Wu, Numerical ranges and compressions of $S_{n}$-matrices, Operators and Matrices 7 (2013), no. 2, 465-476.

[4] K. E. Gustafson And D. K. M. RAO, Numerical range. The field of values of linear operators and matrices, Springer, New York, 1997.

[5] P. R. Halmos, A Hilbert space problem book, second ed., Springer-Verlag, New York, 1982, Encyclopedia of Mathematics and its Applications, 17.

[6] A. N. HAMEd AND I. M. SpITKovsky, On the maximal numerical range of some matrices, Electron. J. Linear Algebra 34 (2018), 288-303.

[7] F. HAUSDORFF, Der Wertvorrat einer Bilinearform, Math. Z. 3 (1919), 314-316.

[8] J. G. STAMPFLI, The norm of a derivation, Pacific J. Math. 33 (1970), 737-747.

[9] O. Toeplitz, Das algebraische Analogon zu einem Satze von Fejér, Math. Z. 2 (1918), no. 1-2, 187-197.

[10] Hai-Yan Zhang, Yan-Ni Dou, Mei-Feng Wang and Hong-Ke Du, On the boundary of numerical ranges of operators, Appl. Math. Lett. 24 (2011), no. 5, 620-622. 